\title{
Pediatric meningiomas: 65-year experience at a single institution
}

\author{
Andrew J. Grossbach, MD, ${ }^{1}$ Kelly B. Mahaney, MD, MS, ${ }^{2}$ and Arnold H. Menezes, MD${ }^{1}$ \\ ${ }^{1}$ Department of Neurosurgery, University of lowa Hospitals and Clinics, lowa City, lowa; and 2 Department of Neurosurgery, \\ University of Virginia, Charlottesville, Virginia
}

\begin{abstract}
OBJECTIVE Meningiomas are relatively common, typically benign neoplasms in adults; however, they are relatively rare in the pediatric population. Pediatric meningiomas behave very differently from their adult counterparts, tending to have more malignant histological subtypes and recur more frequently. The authors of this paper investigate the risk factors, pathological subtypes, and recurrence rates of pediatric meningiomas.
\end{abstract}

METHODS A retrospective chart review was conducted at the University of lowa to identify patients 20 years old and younger with meningiomas in the period from 1948 to 2015.

RESULTS Sixty-seven meningiomas in 39 patients were identified. Eight patients had neurofibromatosis, 2 had a family history of meningioma, and 3 had prior radiation exposure. Twelve (31\%) of the 39 patients had WHO Grade II or III lesions, and $15(38 \%)$ had recurrent lesions after resection.

CONCLUSIONS Pediatric meningiomas should be considered for early treatment and diligent follow-up.

https://thejns.org/doi/abs/10.3171/2017.2.PEDS16497

KEY WORDS pediatric meningioma; radiation; chemotherapy; leukemia; lymphoma; neurofibromatosis; oncology

$\mathrm{M}$ ENINGIOMAS are typically benign tumors that arise from the dura mater. ${ }^{18}$ They account for approximately $20 \%-30 \%$ of all intracranial neoplasms and are found mostly in adults. $.^{18,24,26,33,38} \mathrm{Me}-$ ningiomas account for only about $3 \%$ of all pediatric intracranial neoplasms, and infantile meningiomas are exceedingly rare. ${ }^{6,16,23,24,38,43}$ While meningiomas occur more frequently in females in the adult population, they have a slight male predominance in the pediatric population. ${ }^{16,17,24,25,38}$ In children, these tumors have been shown to behave quite differently from their adult counterparts with atypical or malignant (WHO Grade II or III) meningiomas representing around $20 \%-25 \%$ of cases..$^{25,43}$ Pediatric meningiomas have also been reported to recur more frequently than their adult counterparts. ${ }^{5,39}$ However, given the relative infrequency of pediatric meningiomas, less is known about their development, behavior, and optimal treatment.

Several risk factors associated with meningioma have been identified or explored in the general population, including neurofibromatosis Type 1 (NF1) and Type 2 (NF2). ${ }^{1,5,9,12,14,25,30,34,40}$ Moreover, a history of ionizing radiation has been associated with meningioma forma- tion..$^{13,25,29,31}$ Hormonal factors have been hypothesized to be relevant in meningioma formation given the higher incidence of these lesions in adult women..$^{10,44} \mathrm{~A}$ family history of meningioma may also be a risk factor. ${ }^{7}$ The role of smoking is not clear, but cigarette smoking may increase the risk of meningioma. ${ }^{35}$ Obesity may also be a risk factor. ${ }^{32,42}$

Every histological subtype of meningioma in adults has been described in the pediatric population..$^{33}$ Clear cell (WHO Grade II) and papillary (WHO Grade III) subtypes tend to occur at an earlier age than other subtypes and thus have a higher incidence in the pediatric population. ${ }^{17,20,28,33,34,36,39}$ In 1988 chordoid meningiomas were first described in a series of 7 pediatric patients who had symptoms of Castleman disease (fever, anemia, weight loss, and polyclonal hyperglobulinemia). ${ }^{22,33}$ These symptoms resolved with resection of the tumor and returned with lesion recurrence. However, in a year 2000 study of 42 patients with chordoid meningiomas, only 2 patients were in the pediatric age group. ${ }^{8,33}$

In this paper, we report our experience with meningiomas in the pediatric population and review the available literature.

ABBREVIATIONS BMI = body mass index; NF1 = neurofibromatosis Type 1.

SUBMITTED August 30, 2016. ACCEPTED February 7, 2017.

INCLUDE WHEN CITING Published online May 5, 2017; DOI: 10.3171/2017.2.PEDS16497. 


\section{Methods}

A retrospective chart review was conducted to identify pediatric patients treated for CNS meningioma at the University of Iowa in the period from 1948 to 2015. The study was approved by the institutional review board at the University of Iowa. Meningioma must have been diagnosed within the first 2 decades of life and the diagnosis confirmed via pathology. The medical records of the identified patients were reviewed. Demographic and clinical data were obtained for all patients: age; sex; body mass index (BMI); pathological diagnosis, grade, and subtype; tumor location; multiplicity; history of other malignancies; NF history; family history of meningioma; smoking history; history of radiation exposure and dose; history of chemotherapy exposure; surgical procedures; radiation treatment for meningioma; recurrence; and latency of recurrence. Associations of baseline patient characteristics with WHO grade and recurrence risk (among the at-risk population) were tested using Fisher's exact test. Results with a $\mathrm{p} \leq 0.05$ were considered significant. Statistical analysis for this study was performed using SAS software, version 9.4 of the SAS System for Windows (SAS Institute Inc.).

\section{Results}

Sixty-seven meningiomas were diagnosed in 39 patients ages 20 years and younger. Table 1 summarizes many key findings in these patients. There were 24 females $(62 \%)$ and 15 males (38\%). Mean age at diagnosis was $14.1 \pm 4.57$ years (mean \pm standard deviation, range 1-20 years). Twenty patients (51\%) had tumors involving the skull base. Thirteen patients (33\%) had tumors located in the posterior fossa, $8(20 \%)$ had spinal tumors-2 of which also extended intracranially-and $3(8 \%)$ had intraorbital tumors, including 2 optic nerve sheath tumors. Of the patients with spinal involvement, 5 were female $(62.5 \%)$ and 3 were male (37.5\%). Six patients $(15 \%)$ had multiple lesions at the time of diagnosis. Diagnosis in all but 3 cases was made by pathological examination of a surgical specimen after resection. In 2 cases the diagnosis was made at autopsy. In 1 case, diagnosis of an optic nerve sheath meningioma (fibrous, WHO Grade I) was made via biopsy, but the tumor was not resected. Surgical pathology reports, not the specimens, were reviewed to confirm diagnosis.

\section{Risk Factors}

Neurofibromatosis

Eight patients (20\%) had meningiomas in the setting of NF. Four patients were identified as having NF2, 2 of whom had multiple intracranial meningiomas. Three of these patients were noted to have concurrent bilateral acoustic neuromas, 1 patient had vagal schwannoma and cervical schwannomas, and 1 patient had multiple intramedullary spinal lesions consistent with ependymomas. Three patients - and an unconfirmed fourth case-had NF1, one of whom also had multiple intracranial meningiomas. In these patients, optic gliomas, cervical neurofibroma, cerebellopontine angle schwannoma, cauda equina schwannoma, schwannoma of appendix and pericardium, and neurofibromas of the oculomotor nerves were also observed. Only 2 patients with NF had a meningioma of a higher grade (both were NF2 patients with atypical meningioma). Two patients with NF2 and 2 patients with NF1 had meningioma recurrence following resection.

\section{Family History of Meningioma}

Two patients had a family history of meningioma. In both, the affected family member(s) included the patient's mother. One patient had a mother, a sibling, and several cousins with meningioma, while the other patient only had a mother with a known history of meningioma. Both patients had the clear cell variant of meningioma, whereas only 3 of the 37 patients without a family history of meningioma had clear cell pathology $(p=0.0135$ for association between clear cell pathology and family history of meningioma). One of the 2 patients with a family history of meningioma experienced recurrent disease.

\section{Ionizing Radiation History}

Prior to the diagnosis of meningioma, 3 patients had a history of radiation exposure for the treatment of acute lymphocytic leukemia earlier in childhood. One of these patients had been treated with $1800 \mathrm{cGy}$ in 10 fractions at the age of 2 years. The patient had then undergone wholebody radiation at a dose of $1200 \mathrm{cGy}$ in 6 fractions prior to bone marrow transplant at the age of 6 years. He died at the age of 14 and the diagnosis of meningioma was made at autopsy. A second patient had been treated with 2400 cGy at the age of 4 years and had received chemotherapy consisting of a combination of agents including vincristine, prednisone, Cytoxan, adriamycin, L-asparaginase, VM-26, Ara-C, 6-mercaptopurine, and triple intrathecal therapy. The patient had had a latency of 11 years before being diagnosed with a left sphenoid wing meningioma, which was resected. The pathology was consistent with an atypical (WHO Grade II) meningioma. A third patient had received craniospinal radiation at $1800 \mathrm{cGy}$ when he was 4 years old. At the age of 16 years, after a 12-year latency period, he was diagnosed with a right sphenoid wing meningioma, which was treated surgically. The surgical pathology revealed microcystic meningioma (WHO Grade I).

\section{Smoking History}

Four patients were identified with a history of current (at the time of meningioma diagnosis, 3 patients) or former (1 patient, 12 years old at diagnosis) tobacco use. Three of these 4 patients were female. One patient had pathology consistent with chordoid meningioma; the other 3 patients had WHO Grade I pathology. Two patients with a smoking history experienced tumor recurrence.

\section{Body Mass Index}

Limited BMI data were available for the patients in this review; only 12 patients had BMI data readily available from chart review (in some cases, it was calculated from available height and weight data). Of these 12 patients, 2 were slightly underweight, 6 were normal weight, 1 was overweight, and 3 were obese or morbidly obese. The BMIs included in these data ranged from 18 to $47 \mathrm{~kg} / \mathrm{m}^{2}$. 


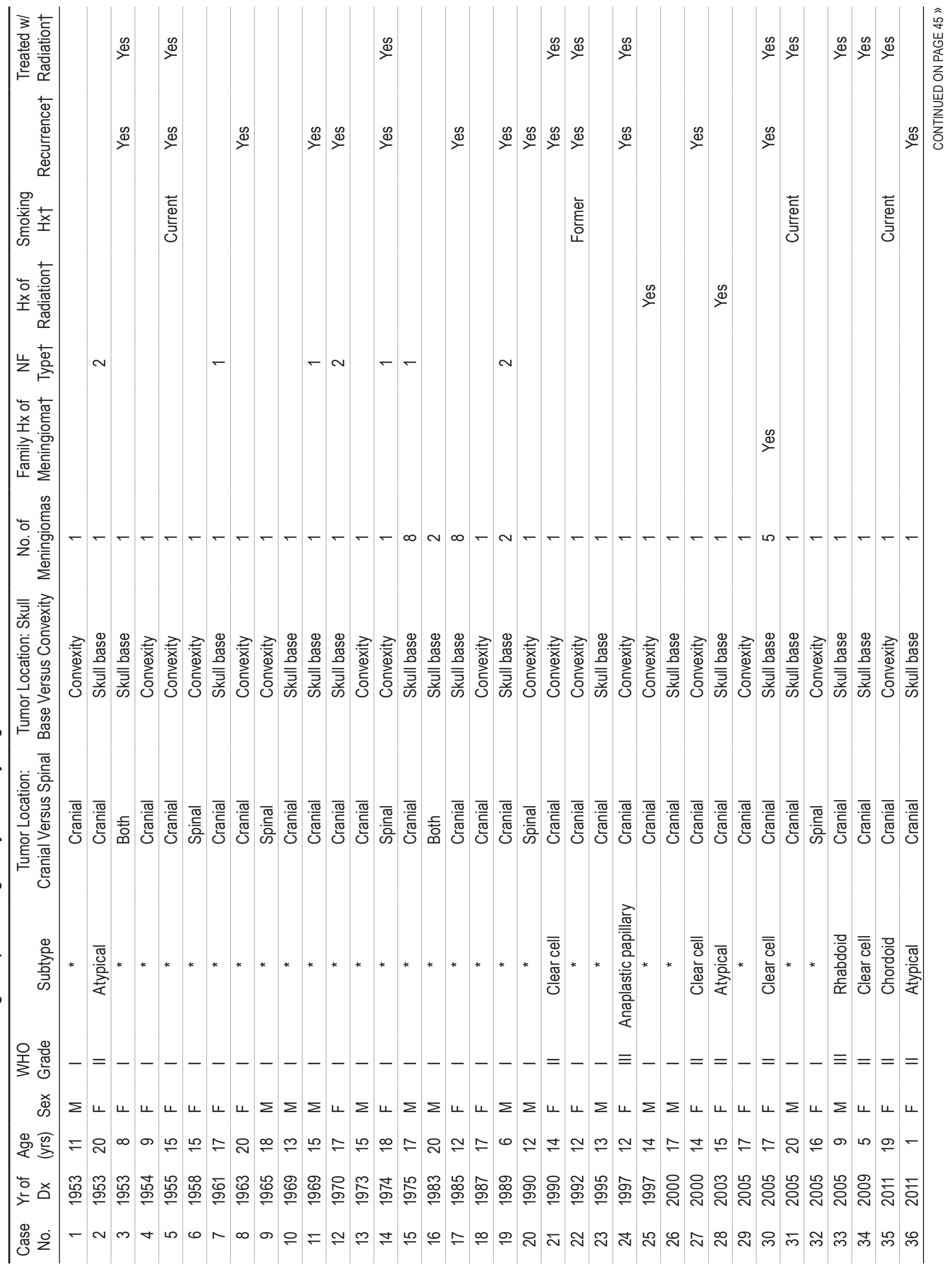




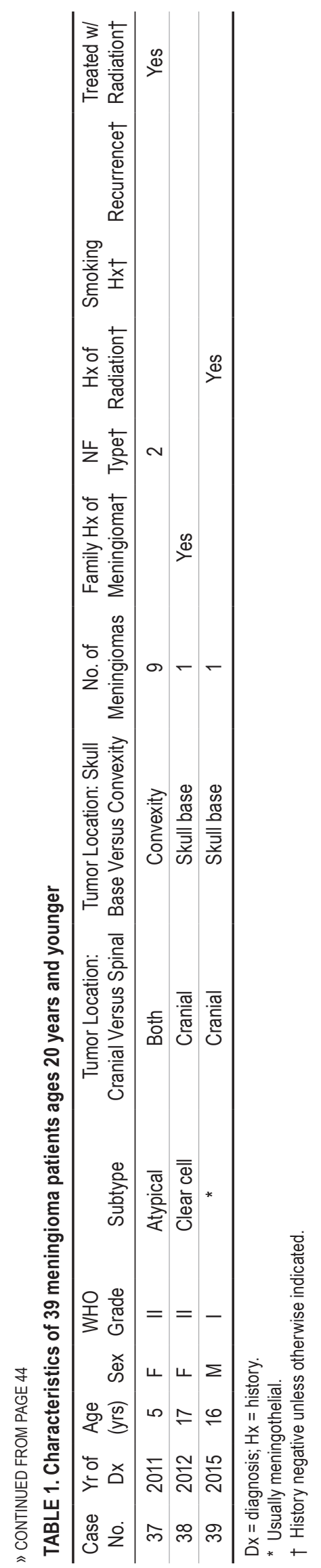

The 3 patients identified as obese or morbidly obese had more aggressive tumor pathology (WHO Grades II and III: chordoid, clear cell, and rhabdoid subtypes). Two of the obese or morbidly obese patients were female; the overweight patient was male. One obese patient experienced meningioma recurrence.

\section{Pathological Subtypes and WHO Grade}

Ten patients $(26 \%)$ had tumors classified as WHO Grade II (22 [33\%] of 67 tumors): 5 patients with clear cell meningioma, 1 with chordoid, and 4 with atypical. Of the patients with clear cell histology, 2 had mothers with the same diagnosis. One of these patients also had a sibling and multiple cousins with meningiomas. This patient, notably, had 5 meningiomas; thus, the clear cell subtype made up 13\% (9/67) of the meningiomas in our series. One patient with the atypical subtype was found to have 9 meningiomas. Two patients (5\%) had WHO Grade III meningiomas (3\% of tumors) with one rhabdoid and one papillary subtype. Note that meningioma grading has changed since the earlier patients in our study were diagnosed and that pathology specimens were not available for review for many of these patients. Therefore, it is possible that even more cases of WHO Grade II and III lesions were unaccounted for. Characteristics associated with meningioma WHO grade are demonstrated in Table 2. Female sex was found to be significantly associated with higher-grade meningioma (Grade II or III vs Grade I, p $=0.0131$ ), as was a younger age $(p=0.0412)$.

\section{Treatment}

Surgery

Of the 39 patients, 36 underwent one or more resection procedures for meningioma. Thirteen patients required multiple surgical procedures (later surgical procedures most often for recurrence). Several patients had 3 or more surgical procedures, and 2 patients each underwent 5 surgical procedures. Details regarding the extent of resection and/or residual tumor versus gross-total resection were not uniformly available. Two patients' meningiomas were identified at autopsy. One of these patients had a history of ionizing radiation for acute lymphoblastic leukemia. The second patient had undergone surgery for vestibular schwannoma and died due to postoperative complications. At autopsy, this patient was found to have 8 intracranial meningiomas. One patient had an optic nerve sheath meningioma, confirmed with biopsy, for which the patient did not receive any further treatment.

\section{Radiation}

Thirteen patients were treated with adjuvant radiation therapy (no patient in this series was treated with radiation as a primary therapy without a surgical procedure). The typical cumulative dose ranged from 52.7 to 64.8 Gy for fractionated therapy. One patient was treated with stereotactic radiosurgery in addition to the fractionated therapy for a total of 5 intracranial meningiomas with clear cell pathology. The primary lesion in this patient was treated surgically, whereas the remaining lesions were mainly treated with radiation. Indications for radiation therapy 
TABLE 2. Characteristics associated with WHO meningioma grade

\begin{tabular}{|c|c|c|c|c|}
\hline Risk Factor & Grade & $\begin{array}{c}\text { Grade } \\
\text { II }\end{array}$ & $\begin{array}{c}\text { Grade } \\
\text { III }\end{array}$ & $\begin{array}{c}p \\
\text { Value* }\end{array}$ \\
\hline No. of patients & 27 & 10 & 2 & \\
\hline No. of lesions & 43 & 22 & 2 & \\
\hline Age & & & & 0.0138 \\
\hline $0-5$ yrs & $0(0)$ & $3(100)$ & $0(0)$ & \\
\hline $6-14$ yrs & $10(71)$ & $2(14)$ & $2(14)$ & \\
\hline $15-20$ yrs & $17(77)$ & $5(23)$ & $0(0)$ & \\
\hline Sex & & & & 0.0075 \\
\hline M & $14(93)$ & $0(0)$ & $1(7)$ & \\
\hline $\mathrm{F}$ & $13(54)$ & $10(42)$ & $1(4)$ & \\
\hline Tumor location & & & & 0.8533 \\
\hline Skull base & $13(65)$ & $6(30)$ & $1(5)$ & \\
\hline Convexity & $14(74)$ & $4(21)$ & $1(5)$ & \\
\hline Tumor location & & & & 0.6260 \\
\hline Cranial & $20(64)$ & $9(29)$ & $2(6)$ & \\
\hline Spinal & $7(88)$ & $1(12)$ & $0(0)$ & \\
\hline$H x$ of NF & & & & 0.5970 \\
\hline None & $21(68)$ & $8(26)$ & $2(6)$ & \\
\hline NF1 & $4(100)$ & $0(0)$ & $0(0)$ & \\
\hline NF2 & $2(50)$ & $2(50)$ & $0(0)$ & \\
\hline $\mathrm{Hx}$ of ionizing radiation & & & & 1.000 \\
\hline Negative & $25(69)$ & $9(25)$ & $2(6)$ & \\
\hline Positive & $2(67)$ & $1(33)$ & $0(0)$ & \\
\hline Family $\mathrm{Hx}$ of meningioma & & & & 0.0891 \\
\hline Negative & $27(73)$ & $8(22)$ & $2(5)$ & \\
\hline Positive & $0(0)$ & $2(100)$ & $0(0)$ & \\
\hline Multiplicity & & & & 0.7526 \\
\hline Solitary meningioma & $23(70)$ & $6(24)$ & $3(6)$ & \\
\hline Multiple meningiomas & $4(67)$ & $2(33)$ & $0(0)$ & \\
\hline Smoking $\mathrm{Hx}$ & & & & 1.000 \\
\hline None & $24(68)$ & $9(26)$ & $2(6)$ & \\
\hline Former (at time of diagnosis) & $1(100)$ & $0(0)$ & $0(0)$ & \\
\hline Current (at time of diagnosis) & $2(67)$ & $1(33)$ & $0(0)$ & \\
\hline $\begin{array}{l}\text { BMI category (data only avail- } \\
\text { able for } 12 \text { patients) }\end{array}$ & & & & 0.4697 \\
\hline$<19$ (underweight) & $2(100)$ & $0(0)$ & $0(0)$ & \\
\hline 19-25 (normal weight) & $2(33)$ & $3(50)$ & $1(17)$ & \\
\hline 25-30 (overweight) & $1(100)$ & $0(0)$ & $0(0)$ & \\
\hline$>30$ (obese) & $0(0)$ & $2(67)$ & $1(33)$ & \\
\hline
\end{tabular}

* Grade I versus Grade II versus Grade III, Fisher's exact test.

were recurrent disease ( 8 patients), aggressive pathology (8 patients), multiplicity ( 2 patients), and subtotal resection and/or surgical inoperability ( 2 patients). Four patients had aggressive pathology and recurrent disease. The 8 patients with aggressive pathology had chordoid (1), clear cell (3), atypical (2), rhabdoid (1), and anaplastic (1) meningiomas. One patient was treated with fractionated radiotherapy following subtotal resection given the tumor's location at the jugular foramen.

\section{Chemotherapy}

One patient was treated with chemotherapy for her meningioma. She underwent subtotal resection of an atypical suprasellar meningioma followed by adjuvant radiation and chemotherapy with bevacizumab and irinotecan. She then received avastin 2 years later for growth of her residual mass. She was 1 year old at the time of the diagnosis of and the first surgery (subtotal resection) for her atypical meningioma. Chemotherapy was used in an attempt to avoid radiation in a very young child. The patient did, at the age of 6 years, ultimately undergo radiation therapy following a second subtotal resection for this very aggressive tumor. As mentioned earlier, 2 patients had a history of chemotherapy treatment for hematological malignancy prior to the diagnosis of meningioma several years later.

\section{Recurrence}

In total, 15 patients (38\%) had a recurrence of their lesion following resection. The average latency to recurrence was $5.78 \pm 5.54$ years (range $1-18$ years). One patient had a distant metastasis to the lumbosacral region from a posterior fossa clear cell meningioma 6 years after diagnosis. Two years later that same patient had a local recurrence in the posterior fossa. Of the meningiomas that recurred locally, 3 were the clear cell type (WHO Grade II), 1 was anaplastic papillary (WHO Grade III), and 1 was the atypical type, which was treated using subtotal resection with adjuvant radiation and chemotherapy. Ten patients with WHO Grade I pathology experienced a local recurrence. The associations of patient characteristics with meningioma recurrence are shown in Table 3 (included are the 36 patients at risk for recurrence, which excludes 2 patients diagnosed at autopsy and 1 patient who did not undergo resection). Although no risk factors demonstrated a statistically significant association with recurrence, the association of female sex with recurrence trended toward but did not reach statistical significance (52\% of females vs $23 \%$ of males with recurrent tumors, $\mathrm{p}=0.1590$; Fig. 1 ).

\section{Discussion}

Our findings correspond to much of the previously published data regarding meningiomas in the pediatric population. We found meningiomas to be more common in older children and adolescents, with a mean age of 14 years at diagnosis, and we observed only 1 infant in our series-similar to data in previous studies. ${ }^{25,38}$

Several risk factors predisposing individuals to meningioma at a young age have been identified, for example, ionizing radiation exposure. . $3,25,29,31$ Ionizing radiation has been shown to cause DNA mutations, either directly or indirectly, via free radicals, which can lead to tumorigenesis. However, the latency to meningioma formation after exposure to cranial radiation is quite long. In 2009, Banerjee et al. looked at acute childhood leukemia patients who had undergone prophylactic cranial radiation. ${ }^{4}$ They reported an average latency of 25 years until meningioma formation. Modan et al. retrospectively reviewed nearly 11,000 patients who had undergone radiation for tinea capitis as children. ${ }^{31}$ These authors noted a 4-fold increase in the incidence of meningioma. The latency to diagnosis ranged 
TABLE 3. Characteristics in association with meningioma recurrence in 36 patients who underwent resection*

\begin{tabular}{|c|c|c|c|}
\hline Risk Factor & $\begin{array}{c}\text { No } \\
\text { Recurrence } \\
(\%)\end{array}$ & $\begin{array}{l}\text { Recurrence } \\
(\%)\end{array}$ & $\begin{array}{c}\mathrm{p} \\
\text { Value }\end{array}$ \\
\hline No. of patients & 21 & 15 & \\
\hline Age & & & 0.2029 \\
\hline $0-5$ yrs & $2(67)$ & $1(33)$ & \\
\hline $6-14$ yrs & $5(38)$ & $8(62)$ & \\
\hline $15-20$ yrs & $14(70)$ & $6(30)$ & \\
\hline Sex & & & 0.1590 \\
\hline M & $10(77)$ & $3(23)$ & \\
\hline $\mathrm{F}$ & $11(48)$ & $12(52)$ & \\
\hline WHO grade & & & 1.000 \\
\hline I & $14(58)$ & $10(42)$ & \\
\hline II & $6(60)$ & $4(40)$ & \\
\hline III & $1(50)$ & $1(50)$ & \\
\hline Tumor location & & & 0.7360 \\
\hline Skull base & $12(63)$ & $7(37)$ & \\
\hline Convexity & $9(53)$ & $8(47)$ & \\
\hline Tumor location & & & 1.000 \\
\hline Cranial & $16(57)$ & $12(43)$ & \\
\hline Spinal & $5(62)$ & $3(38)$ & \\
\hline Hx of NF & & & 0.6860 \\
\hline None & $18(62)$ & $11(38)$ & \\
\hline NF1 & $1(33)$ & $2(67)$ & \\
\hline NF2 & $2(50)$ & $2(50)$ & \\
\hline $\mathrm{Hx}$ of ionizing radiation & & & 0.5000 \\
\hline Negative & $19(56)$ & $15(44)$ & \\
\hline Positive & $2(100)$ & $0(0)$ & \\
\hline Family $\mathrm{Hx}$ of meningioma & & & 1.000 \\
\hline Negative & $20(59)$ & $14(41)$ & \\
\hline Positive & $1(50)$ & $1(50)$ & \\
\hline Multiplicity & & & 0.6296 \\
\hline Solitary meningioma & $19(61)$ & $12(39)$ & \\
\hline Multiple meningiomas & $2(40)$ & $3(60)$ & \\
\hline Smoking $\mathrm{Hx}$ & & & 0.7460 \\
\hline None & $19(59)$ & $13(41)$ & \\
\hline Former (at time of diagnosis) & $0(0)$ & $1(100)$ & \\
\hline Current (at time of diagnosis) & $2(67)$ & $1(33)$ & \\
\hline $\begin{array}{l}\text { BMI category (data only avail- } \\
\text { able for } 12 \text { patients) }\end{array}$ & & & 0.7403 \\
\hline$<19$ (underweight) & $1(50)$ & $1(50)$ & \\
\hline 19-25 (normal weight) & $2(33)$ & $4(67)$ & \\
\hline 25-30 (overweight) & $1(100)$ & $0(0)$ & \\
\hline$>30$ (obese) & $2(67)$ & $1(23)$ & \\
\hline
\end{tabular}

* Excluding 2 patients diagnosed at autopsy and 1 patient with optic nerve sheath meningioma that was not treated surgically, all with WHO Grade I pathology.

† Fisher's exact test.

from 16 to 21 years after irradiation. Iacono et al. reported a latency between 20.8 and 31.1 years after irradiation at low and high doses, respectively. ${ }^{21}$ Given this long latency, $p=0.0886$, log-rank test

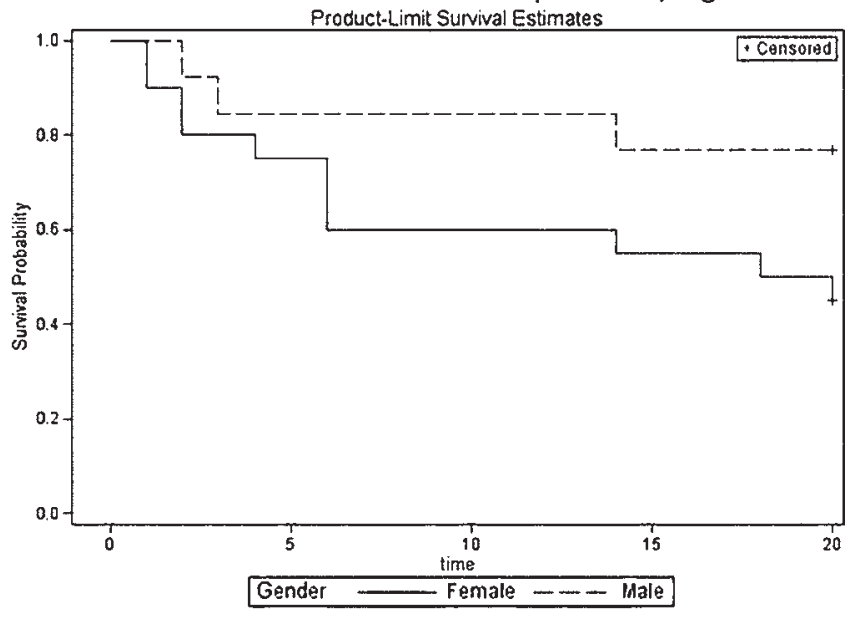

FIG. 1. Recurrence-free survival by patient sex.

most meningiomas caused by cranial irradiation in childhood will present in the young adult population rather than the pediatric population. Radiation-induced meningioma tends to have more aggressive behavior, has a higher incidence of recurrence, and is more likely to be multifocal than sporadic meningioma. ${ }^{5}$ Nonetheless, 3 patients in our study had a history of ionizing radiation for childhood lymphoproliferative disease. In 2 patients the latency between radiation and meningioma diagnosis was 12 years, and in both of them the pathology was WHO Grade I; latency in the third patient was 11 years and the diagnosis was WHO Grade II atypical meningioma.

In some cases, a family history of meningioma has been identified as a contributing risk factor., ${ }^{7,44}$ However, such a family history has not been reported in prior pediatric meningioma series. In our study, 2 patients had a family history of meningioma, and in both cases the pathology was consistent with clear cell meningioma $(p=0.0891$ for association with WHO grade). One patient had 5 meningiomas and required treatment for recurrence. The other patient has not experienced a recurrence to date.

A history of NF may be a risk factor for meningioma in children..$^{34}$ Neurofibromatosis Type 2 has been shown to increase the risk of developing intracranial meningioma ${ }^{1,5}$, $12,14,25,30,34,40$ and has been reported in $6 \%-39 \%$ of pediatric meningioma cases. ${ }^{33,37,38}$ Neurofibromatosis Type 1 has not shown a similar increased incidence; however, one series of 29 pediatric meningiomas included 7 patients with NF1. ${ }^{14,25}$ The NF2-related meningiomas show pathological and genotypic features similar to those in sporadic meningiomas; however, they tend to show multiplicity more frequently than the sporadic meningiomas. ${ }^{25,27}$ Despite a distribution of subtypes similar to that in sporadic meningiomas, NF2associated meningiomas have been reported to demonstrate increased mitotic activity. ${ }^{2}$ Patients with NF2 also have a higher risk of spinal, as well as optic nerve, meningiomas..$^{25}$ Meningiomas are seen in up to $53 \%$ of NF2 patients and in up to $83 \%$ of patients with the more severe phenotype known as the Wishart variant. ${ }^{15}$ Nonetheless, it is estimated that only around $1 \%$ of all meningioma patients carry a diagnosis of NF2 ${ }^{34}$ However, pediatric patients with NF2 
are much more likely to present with meningiomas, with a diagnosis in 7\%-41\% of patients with NF2. 1,5,12,14,30,34,40

We found both patients with a history of NF1 and patients with a history of NF2 in our study of pediatric meningiomas. Eight of the 39 patients had a history of NF: 4 with NF1 and 4 with NF2. This finding is in keeping with those in previous reports. And, in our study, NF was the most commonly observed predisposing factor for meningioma in children. Similar to authors of previous reports, ${ }^{33}$ we found that a history of NF did not have a statistically significantly association with WHO grade or recurrence.

Multiplicity has been variably reported in pediatric meningioma. In our series 6 patients had multiple meningiomas. In many cases documented in the literature, multiplicity was wholly accounted for by a concurrent diagnosis of $\mathrm{NF}^{3,34,43}$ as patients with NF2 are known to be at risk for multiple CNS tumors (not only meningioma). However, multiplicity has been reported in association with radiation-induced meningioma ${ }^{4,18}$ and in sporadic meningioma in children. ${ }^{11}$ In our study, 3 of 6 patients with multiple meningiomas had a concurrent diagnosis of NF. In none of the 6 patients were the meningiomas induced by radiation.

Other risk factors, such as the influence of hormones, obesity, and smoking, were somewhat more difficult to assess in our retrospective analysis. We reviewed charts for hormone-related disease or the use of exogenous hormones, but we did not find any evidence to suggest that any of the meningiomas were hormonally influenced. A few patients either had a smoking history or were obese. While the presence of these factors may have contributed to the risk of developing meningioma in these patients, it would be difficult to make such a conclusion, and no significant associations with WHO grade or recurrence were identified.

While prior studies have indicated a male predominance for meningioma in the pediatric population - the converse of the female predominance in adults-we did not find a male predominance in our study. ${ }^{16,17,24,25,38}$ In fact, female patients outnumbered the male patients (24:15). Moreover, we found a significant association between female sex and WHO grade, with higher-grade meningiomas observed more frequently in females $(46 \%$ Grades II and III in females vs $7 \%$ Grades II and III in males, $\mathrm{p}=0.0131)$. To our knowledge, this finding has not been reported. Female sex was the only significant risk factor we identified for a higher WHO grade. We also found a nonsignificant trend toward higher recurrence rates in females $(52 \%$ vs $23 \%, \mathrm{p}$ $=0.1590$; Fig. 1), which did not seem to be wholly accounted for by a higher WHO grade (recurrence rate of $54 \%$ in females with Grade I meningioma vs $45 \%$ in females with Grade II or III meningioma, not significant). This challenges the notion that meningioma is a disease process affecting predominantly males in the pediatric population. It also draws attention to the fact that among children and adolescents with meningioma, girls may be at higher risk than boys for aggressive tumors.

Although pediatric meningiomas are quite rare, they are a recognized disease entity in the pediatric population and should be considered in the differential diagnosis of a newly diagnosed extraaxial cranial or spinal mass lesion, particularly when it demonstrates characteristic imaging features such as a dural tail, convexity, or skull base lo- cation and a homogeneous enhancement pattern. While certain risk factors, such as a history of NF, prior ionizing radiation, or a family history of meningioma, should raise suspicion for a diagnosis of meningioma, the absence of these predisposing factors does not effectively eliminate the risk of meningioma in the pediatric population. The majority of patients in our series (26 [67\%] of 39) had none of the above risk factors.

Pediatric meningiomas tend to be more aggressive than their adult counterparts. This is reflected in the literature as well as in our findings. ${ }^{24,43}$ Approximately onethird of the patients in our study had more aggressive pathology: 31\% (12 of 39) of patients had WHO Grade II or Grade III pathology. We also found that a female sex and younger age were significantly associated with a higher WHO grade pathology - which to our knowledge has not been previously reported. Five of those cases (42\%) were the clear cell subtype. Given pediatric meningiomas' propensity for aggressive behavior, early intervention in newly diagnosed cases should be considered, or at least frequent follow-up imaging in the case of a small lesion. Pediatric meningiomas also tend to recur more frequently than their adult counterparts.,39 In our study, 15 (42\%) of the 36 patients who had undergone resection had lesion recurrence, with a mean latency to recurrence of 5.78 years. Among the 15 patients with recurrence, 5 (33\%) had WHO Grade II or III pathology (Figs. 2 and 3), and the lesions in 3 of them were the clear cell subtype. It is well established that WHO Grade II and III lesions have a higher likelihood of recurrence; however, our findings highlight the fact that even low-grade lesions in children can behave more aggressively and thus require more diligent surveillance for recurrence. Among our patients with WHO Grade I pathology, the recurrence rate was 42\% (10 of 24), which was not significantly different from the recurrence rate among patients with WHO Grade II or III pathology. This finding suggests that even WHO Grade I meningiomas in children may behave more like adult atypical meningiomas than classic adult meningothelial meningiomas. ${ }^{19}$ Given this finding, it is possible that the WHO grading system may not adequately reflect how ag-

$p=0.9233$, log-rank test

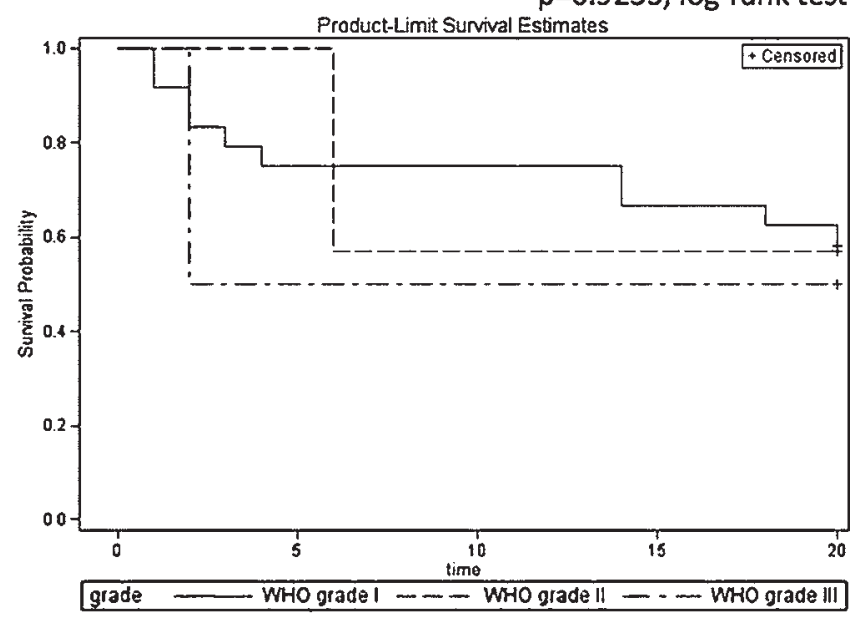

FIG. 2. Recurrence-free survival by WHO grade: I vs II vs III. 
$p=0.9239$, log-rank test

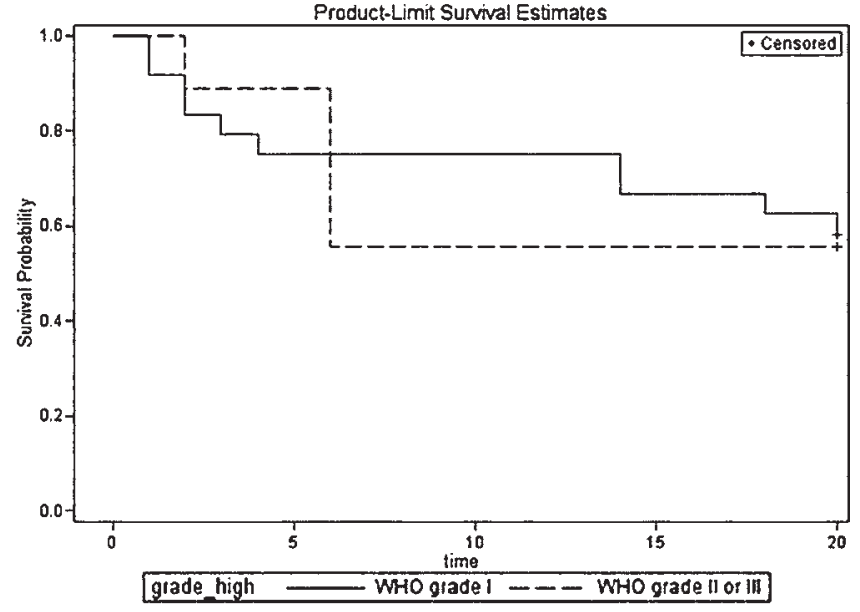

FIG. 3. Recurrence-free survival by WHO grade: I vs II/III.

gressive a meningioma will be in this age group and that further classification is necessary.

\section{Study Limitations}

Our study has several limitations. As a retrospective review, certain clinically relevant data, such as extent of resection, were not uniformly available, and we were without the means to objectively define such criteria through chart review. Furthermore, resection is undoubtedly relevant with regard to recurrence rates. It is possible that the higher recurrence rates we observed are in fact related to the extent of initial resection and actually represent tumor progression. This is especially relevant with regard to the earlier cases from the pre-MRI era in which verification of the extent of resection was extremely limited. Thus, it is difficult to distinguish true recurrence from progression in this series. However, by the same token, many valuable historical series would have to be disregarded on these premises. Furthermore, advances in adjuvant therapy such as stereotactic radiosurgery were unavailable in the earlier patients in the study, thus potentially influencing recurrence rates for subtotally resected tumors.

Another limitation is the inconsistency of pathology reporting in the earlier cases. It is notable that for a number of patients, the pathology reports actually predate the first publication of the WHO classification of tumors of the CNS in 1979.41 Many of these cases provided descriptive pathology reports from which the current WHO grade could be inferred (for example, description of meningothelial, fibrous/fibroblastic, or psammomatous meningioma can safely be categorized as WHO Grade I, while the description of atypical meningioma can be safely determined to be WHO Grade II). However, 15 patients in our series $(42 \%)$ had pathology predating the first WHO classification publication, and any inferences about pathology grade as it relates to recurrence rate or treatment in this series must take this into consideration.

\section{Conclusions}

Meningiomas are relatively rare lesions in the pediatric population. Although there are several known risk factors, many of which were observed in the patients in our study, the absence of these risk factors does not eliminate the meningioma risk; sporadic meningiomas can be observed in children. In our series, meningiomas were observed more frequently in girls than in boys and exhibited more aggressive pathological histology and WHO grade in girls than in boys. Pediatric meningioma should be thought of as an entity separate from its adult counterpart as it behaves more aggressively on the whole. Early treatment should be considered, and close follow-up is mandatory.

\section{Acknowledgments}

We extend special thanks to Mary Jo Piper and Jean Quinlan for contributions to data collection and manuscript preparation.

\section{References}

1. Amirjamshidi A, Mehrazin M, Abbassioun K: Meningiomas of the central nervous system occurring below the age of 17 : report of 24 cases not associated with neurofibromatosis and review of literature. Childs Nerv Syst 16:406-416, 2000

2. Antinheimo J, Haapasalo H, Haltia M, Tatagiba M, Thomas $\mathrm{S}$, Brandis A, et al: Proliferation potential and histological features in neurofibromatosis 2-associated and sporadic meningiomas. J Neurosurg 87:610-614, 1997

3. Athanasiou A, Magras I, Sarlis P, Spyridopoulos E, Polyzoidis $\mathrm{K}$ : Anterolateral meningioma of the foramen magnum and high cervical spine presenting intradural and extradural growth in a child: case report and literature review. Childs Nerv Syst 31:2345-2351, 2015

4. Banerjee J, Pääkkö E, Harila M, Herva R, Tuominen J, Koivula A, et al: Radiation-induced meningiomas: a shadow in the success story of childhood leukemia. Neuro Oncol 11:543-549, 2009

5. Baumgartner JE, Sorenson JM: Meningioma in the pediatric population. J Neurooncol 29:223-228, 1996

6. Caroli E, Russillo M, Ferrante L: Intracranial meningiomas in children: report of 27 new cases and critical analysis of 440 cases reported in the literature. J Child Neurol 21:3136, 2006

7. Claus EB, Calvocoressi L, Bondy ML, Schildkraut JM, Wiemels JL, Wrensch M: Family and personal medical history and risk of meningioma. J Neurosurg 115:1072-1077, 2011

8. Couce ME, Aker FV, Scheithauer BW: Chordoid meningioma: a clinicopathologic study of 42 cases. Am J Surg Pathol 24:899-905, 2000

9. Créange A, Zeller J, Rostaing-Rigattieri S, Brugières P, Degos JD, Revuz J, et al: Neurological complications of neurofibromatosis type 1 in adulthood. Brain 122:473-481, 1999

10. Custer B, Longstreth WT Jr, Phillips LE, Koepsell TD, Van Belle G: Hormonal exposures and the risk of intracranial meningioma in women: a population-based case-control study. BMC Cancer 6:152, 2006

11. Darling CF, Byrd SE, Reyes-Mugica M, Tomita T, Osborn RE, Radkowski MA, et al: MR of pediatric intracranial meningiomas. AJNR Am J Neuroradiol 15:435-444, 1994

12. Deen HG Jr, Scheithauer BW, Ebersold MJ: Clinical and pathological study of meningiomas of the first two decades of life. J Neurosurg 56:317-322, 1982

13. Elbabaa SK, Gokden M, Crawford JR, Kesari S, Saad AG: Radiation-associated meningiomas in children: clinical, pathological, and cytogenetic characteristics with a critical review of the literature. J Neurosurg Pediatr 10:281-290, 2012

14. Erdinçler P, Lena G, Sarioğlu AC, Kuday C, Choux M: Intracranial meningiomas in children: review of 29 cases. Surg Neurol 49:136-141, 1998 
15. Evans DG, Huson SM, Donnai D, Neary W, Blair V, Newton V, et al: A clinical study of type 2 neurofibromatosis. Q J Med 84:603-618, 1992

16. Ferrante L, Acqui M, Artico M, Mastronardi L, Rocchi G, Fortuna A: Cerebral meningiomas in children. Childs Nerv Syst 5:83-86, 1989

17. Germano IM, Edwards MS, Davis RL, Schiffer D: Intracranial meningiomas of the first two decades of life. J Neurosurg 80:447-453, 1994

18. Goshen Y, Stark B, Kornreich L, Michowiz S, Feinmesser M, Yaniv I: High incidence of meningioma in cranial irradiated survivors of childhood acute lymphoblastic leukemia. Pediatr Blood Cancer 49:294-297, 2007

19. Hasan S, Young M, Albert T, Shah AH, Okoye C, Bregy A, et al: The role of adjuvant radiotherapy after gross total resection of atypical meningiomas. World Neurosurg 83:808815,2015

20. Heth JA, Kirby P, Menezes AH: Intraspinal familial clear cell meningioma in a mother and child. Case report. J Neurosurg 93 (2 Suppl):317-321, 2000

21. Iacono RP, Apuzzo ML, Davis RL, Tsai FY: Multiple meningiomas following radiation therapy for medulloblastoma. Case report. J Neurosurg 55:282-286, 1981

22. Kepes JJ, Chen WY, Connors MH, Vogel FS: "Chordoid" meningeal tumors in young individuals with peritumoral lymphoplasmacellular infiltrates causing systemic manifestations of the Castleman syndrome. A report of seven cases. Cancer 62:391-406, 1988

23. Kolluri VR, Reddy DR, Reddy PK, Naidu MR, Rao SB, Sumathi C: Meningiomas in childhood. Childs Nerv Syst 3:271-273, 1987

24. Kotecha RS, Junckerstorff RC, Lee S, Cole CH, Gottardo NG: Pediatric meningioma: current approaches and future direction. J Neurooncol 104:1-10, 2011

25. Kotecha RS, Pascoe EM, Rushing EJ, Rorke-Adams LB, Zwerdling T, Gao X, et al: Meningiomas in children and adolescents: a meta-analysis of individual patient data. Lancet Oncol 12:1229-1239, 2011

26. Longstreth WT Jr, Dennis LK, McGuire VM, Drangsholt MT, Koepsell TD: Epidemiology of intracranial meningioma. Cancer 72:639-648, 1993

27. Louis DN, Ramesh V, Gusella JF: Neuropathology and molecular genetics of neurofibromatosis 2 and related tumors. Brain Pathol 5:163-172, 1995

28. Ludwin SK, Rubinstein LJ, Russell DS: Papillary meningioma: a malignant variant of meningioma. Cancer 36:13631373,1975

29. Menon G, Nair S, Sudhir J, Rao BRM, Mathew A, Bahuleyan B: Childhood and adolescent meningiomas: a report of 38 cases and review of literature. Acta Neurochir (Wien) 151:239-244, 2009

30. Merten DF, Gooding CA, Newton TH, Malamud N: Meningiomas of childhood and adolescence. J Pediatr 84:696-700, 1974

31. Modan B, Baidatz D, Mart H, Steinitz R, Levin SG: Radiation-induced head and neck tumours. Lancet 1:277-279, 1974

32. Niedermaier T, Behrens G, Schmid D, Schlecht I, Fischer B, Leitzmann MF: Body mass index, physical activity, and risk of adult meningioma and glioma: a meta-analysis. Neurology 85:1342-1350, 2015

33. Perry A, Dehner LP: Meningeal tumors of childhood and infancy. An update and literature review. Brain Pathol 13:386-408, 2003

34. Perry A, Giannini C, Raghavan R, Scheithauer BW, Banerjee R, Margraf L, et al: Aggressive phenotypic and genotypic features in pediatric and NF2-associated meningiomas: a clinicopathologic study of 53 cases. J Neuropathol Exp Neurol 60:994-1003, 2001

35. Phillips LE, Longstreth WT Jr, Koepsell T, Custer BS, Kukull WA, van Belle G: Active and passive cigarette smoking and risk of intracranial meningioma. Neuroepidemiology 24:117-122, 2005

36. Pimentel J, Fernandes A, Pinto AE, Fonseca I, Moura Nunes JF, Lobo Antunes J: Clear cell meningioma variant and clinical aggressiveness. Clin Neuropathol 17:141-146, 1998

37. Ravindranath K, Vasudevan MC, Pande A, Symss N: Management of pediatric intracranial meningiomas: an analysis of 31 cases and review of literature. Childs Nerv Syst 29:573-582, 2013

38. Rushing EJ, Olsen C, Mena H, Rueda ME, Lee YS, Keating $\mathrm{RF}$, et al: Central nervous system meningiomas in the first two decades of life: a clinicopathological analysis of $87 \mathrm{pa}-$ tients. J Neurosurg 103 (6 Suppl):489-495, 2005

39. Sandberg DI, Edgar MA, Resch L, Rutka JT, Becker LE, Souweidane MM: MIB-1 staining index of pediatric meningiomas. Neurosurgery 48:590-597, 2001

40. Sano K, Wakai S, Ochiai C, Takakura K: Characteristics of intracranial meningiomas in childhood. Childs Brain 8:98106,1981

41. Scheithauer BW: Development of the WHO classification of tumors of the central nervous system: a historical perspective. Brain Pathol 19:551-564, 2009

42. Sergentanis TN, Tsivgoulis G, Perlepe C, Ntanasis-Stathopoulos I, Tzanninis IG, Sergentanis IN, et al: Obesity and risk for brain/CNS tumors, gliomas and meningiomas: a metaanalysis. PLoS One 10:e0136974, 2015

43. Thuijs NB, Uitdehaag BMJ, Van Ouwerkerk WJR, van der Valk P, Vandertop WP, Peerdeman SM: Pediatric meningiomas in The Netherlands 1974-2010: a descriptive epidemiological case study. Childs Nerv Syst 28:1009-1015, 2012

44. Wiemels J, Wrensch M, Claus EB: Epidemiology and etiology of meningioma. J Neurooncol 99:307-314, 2010

\section{Disclosures}

The authors report no conflict of interest concerning the materials or methods used in this study or the findings specified in this paper.

\section{Author Contributions}

Conception and design: Menezes. Acquisition of data: Grossbach, Mahaney. Analysis and interpretation of data: Grossbach, Mahaney. Drafting the article: Grossbach, Mahaney. Critically revising the article: Grossbach, Mahaney. Reviewed submitted version of manuscript: all authors. Statistical analysis: Mahaney. Study supervision: Menezes.

\section{Supplemental Information}

Previous Presentations

Portions of this work were presented in poster form at the 83rd American Association of Neurological Surgeons Annual Scientific Meeting held in Washington, DC, in May 2015.

\section{Correspondence}

Andrew Grossbach, Department of Neurosurgery, University of Iowa Hospitals and Clinics, 200 Hawkins Dr., Iowa City, IA 52245. email: andrew-grossbach@uiowa.edu. 